\title{
Update: Electronic Transactions, hipAA, and Medicare REIMBURSEMENT
}

\author{
Erin Brisbay McMahon, JD
}

Physician practices that transmit any health information in electronic form in connection with a transaction covered by the HIPAA transactions and code sets rule will be required to comply with the rule no later than October 16, 2003. Under the rule, if certain transactions, such as the filing of claims, are conducted electronically, they must contain certain data content and be formatted in a particular way.

On and after October 16, 2003, Medicare will require claims to be submitted electronically unless a physician practice has less than 10 full-time equivalent employees. Practices with fewer than 10 FTEs can continue to submit paper claims to Medicare with-

\section{The Transactions and Code Sets} STANDARDS

On August 17, 2000, the Department for Health and Human Services (HHS) issued the final rule that governs electronic exchanges of financial and administrative information in the health care industry (1). HHS was required to adopt the rule, known as the Transactions and Code Sets Standards (TCS rule), pursuant to the administrative simplification provisions in the Health Insurance Portability and Accountability Act of 1996 (HIPAA) (2). Congress and the regulators hoped that adoption of the TCS rule would simplify electronic transactions and result in cost savings throughout the industry (3). Technical corrections were made to the TCS rule on November 24, 2000 (4), and the TCS rule was modified on February 20, 2003 (5).

The TCS rule applies to all health care providers who transmit any health information in electronic form in connection

From Wyatt, Tarrant \& Combs Lexington, KY. Address Correspondence: Erin Brisbay McMahon, JD, 250 W. Main St., Suite 1600 , Lexington, Kentucky 40507.E-mail: emcmahon@wyattfirm.com

Funding: There was no external funding in preparation of this manuscript. out any further action on their part.

At a minimum, physician practices must have the ability to capture the data required by the rule for covered transactions conducted electronically, and either use a clearinghouse to translate the data to $\mathrm{X}_{12} \mathrm{~N}$ format or obtain a translator and electronic connectivity to ensure that the practice can send electronically compliant claims by October 16, 2003.

Trading partner agreements may specify the duties and responsibilities of each party to the agreement in conducting a covered transaction electronically, but they are not required under HIPAA. Business associate agreements are required under HIPAA if a practice chooses to use a business associate (a person who performs an activity falling under the rule on behalf of the practice), including a health care clearinghouse, to conduct electronic covered transactions for it, and the agreement must comply with the HIPAA transactions and code sets rule, the privacy rule, and the security rule.

This article is not, and should not be construed as, legal advice or an opinion on specific situations.

Keywords: HIPAA, transactions and code sets, electronic transactions, covered transactions, electronic standards, health claims, health care clearinghouses

with a transaction covered by the TCS rule. It also applies to health care plans and health care clearinghouses (6). Health care plans include most private sector health plans that provide or pay the cost of medical care (e.g., managed care organizations), and all government health plans (including Medicare and Medicaid) (7). Health care clearinghouses are public or private entities that either (a) take information received from another entity (e.g., a physician group practice) in a nonstandard format or containing nonstandard data content and convert it into a standard transaction or standard data elements for a receiving entity (e.g., a health plan) or (b) receive a standard transaction from another entity (e.g., a health plan) and convert it into nonstandard format or nonstandard data content for a receiving entity (e.g., a physician group practice) (8). A physician practice that conducts transactions covered under the TCS rule (such as filing a claim) electronically through a clearinghouse falls under the TCS rule and must conform to all aspects of the HIPAA administrative simplification regulations on their respective compliance deadline dates (e.g., the privacy rule, the security rule, and the TCS rule) (9).
Health Care Transactions Subject to the TCS Rule

Under the TCS rule, an electronic transaction involves information exchanges between two parties to carry out financial or administrative activities related to health care. Transactions subject to the TCS rule, known as "covered transactions," include the following types of electronic data interchange:

- Health claims and equivalent encounter information - a request by health care from a health plan or encounter information for the purpose of reporting health care (10);

- Enrollment and disenrollment in a health plan - the transmission of subscriber enrollment information to a health plan to establish or terminate coverage (11);

- Eligibility for a health plan - an inquiry by a provider to a health plan or between health plans regarding an enrollee's eligibility to receive health care under a plan, coverage of health care under the plan, or benefits associated with the plan, or the response to that inquiry (12); a provider to obtain payment for 
- Health care payment and remittance advice - the transmission of payment or information about the transfer of funds from a health plan to a provider's financial institution or the transmission of an explanation of benefits or remittance advice from a health plan to a provider (13);

- Health plan premium payments - the transmission of payment, information about the transfer of funds, detailed remittance information about individuals for whom premiums are being paid, or payment processing information to transmit health care premium payments from the entity that is arranging for the provision of health care or is providing health care coverage payments to the health plan (14);

- Health claim status - an inquiry to determine the status of a claim, or the response to the inquiry (15)

- Referral certification and authorization - a request for review of health care to obtain authorization for the care, a request to obtain authorization for a referral, or a response to either of these requests (16); or

- Coordination of benefits - the transmission from any entity to a health plan for the purpose of determining the relative payment responsibilities of the health plan concerning claims or payment information (17).

Physicians conducting any of these transactions electronically will be able to use a standard format to determine a patient's eligibility for insurance coverage, file a claim, ask about the status of a claim, request authorizations for services or specialist referrals, and receive electronic remittances to post receivables. Similarly, health plans will be able to pay physicians, authorize services, certify referrals, and coordinate benefits using a standard electronic format for each transaction. HHS will eventually adopt standards for claims attachments and the first report of injury (18).

Conflicting state laws will be superseded by the standards, although HHS is developing an exception process pursuant to HIPAA. Specific exceptions to the standards may also be allowed for entities wishing to test (a) a modification to an existing standard or (b) a different standard (19).

\section{What Are the Standards?}

HIPAA required HHS to adopt data and format standards for the covered transactions, if possible, that were developed by private sector standards development organizations accredited by the American National Standards Institute (ANSI) (20). ANSI Accredited Standards Committee (ASC) X12N standards, Version 4010-A-1 are the standards adopted for the electronic covered transactions listed above (21). Retail pharmacies have their own set of standards, which are not discussed here. Each implementation guide for each of the standards is several hundred pages long and can be obtained online at $h t t p: / / w w w . w p c-e d i$. Specifically, the standards are:

- 837P or ASC X12N 837 - used for health claims and equivalent encounter information in place of the CMS-1500 or NSF electronic format, and for coordination of benefits, and called "Health Care Claim: Professional" (22);

- 834 or ASC X12N 834 - used for enrollment and disenrollment in a health plan and called "Benefit Enrollment and Maintenance" - physician practices may use this electronic transaction to enroll and disenroll employees from their health plan (23);

- 270 or ASC X12N 270 - used to determine eligibility for a health plan and called "Health Care Eligibility Benefit Inquiry", and 271 or ASC X12N 271 - used to respond to that inquiry and called "Health Care Eligibility Benefit Response” (24);

- 835 or ASC X12N 835 - Health Care Claim Payment/Advice - the standard for an explanation of benefits from the health plan (25);

- 820 or ASC X12N 820 - used for health plan premium payments and called the "Payroll Deducted and Other Group Premium Payment for Insurance Products" standard (26);

- 276 or ASC X12N 276 - Health Care Claim Status Request, and 277 or ASC X12N 277 - used to respond to that inquiry and called "Health Care Claim Status Response" (27); and

- 278 or ASC X12N 278 - used for referral certification and authorization requests and responses and called a "Health Care Services Review - Request for Review and Response" (28).
When conducting a covered transaction electronically, physicians are required to use applicable medical data code sets as specified in the implementation specification that is valid at the time the health care is furnished. Under the TCS rule, a "code set" is any set of codes used for encoding data elements, such as tables of terms, medical concepts, medical diagnostic codes, or medical procedure codes. The standard medical data code sets that must be used to code electronic covered transactions on and after October 16, 2003 are as follows:

- International Classification of Diseases, 9th Edition, Clinical Modification, (ICD-9-CM), Volumes 1 and 2 (including The Official ICD-9-CM Guidelines for Coding and Reporting), as maintained and distributed by HHS, for the following conditions:

1. Diseases.

2. Injuries

3. Impairments.

4. Other health problems and their manifestations.

5. Causes of injury, disease, impairment, or other health problems (29).

- International Classification of Diseases, 9th Edition, Clinical Modification, Volume 3 Procedures (including the Official ICD-9-CM Guidelines for Coding and Reporting), as maintained and distributed by HHS, for the following procedures or other actions taken for diseases, injuries, and impairments on hospital inpatients reported by hospitals:

1. Prevention.

2. Diagnosis.

3. Treatment.

4. Management (30).

Code on Dental Procedures and Nomenclature, as maintained and distributed by the American Dental Association, for dental services (31).

- The combination of Health Care Financing Administration Common Procedure Coding System (HCPCS), as maintained and distributed by HHS, and Current Procedural Terminology, Fourth Edition (CPT-4), as maintained and distributed by the American Medical Association, for physician services and other health 
care services. These services include, but are not limited to, the following:

1. Physician services.

2. Physical and occupational therapy services.

3. Radiologic procedures.

4. Clinical laboratory tests.

5. Other medical diagnostic procedures.

6. Hearing and vision services.

7. Transportation services including ambulance (32).

- The Health Care Financing Administration Common Procedure Coding System (HCPCS), as maintained and distributed by HHS, for all other substances, equipment, supplies, or other items used in health care services, with the exception of drugs and biologics. These items include, but are not limited to, the following:

1. Medical supplies.

2. Orthotic and prosthetic devices.

3. Durable medical equipment (33).

Local and proprietary codes still in use by health plans can no longer be used in electronic covered transactions after October 16, 2003 (34).

\section{The Interaction of Medicare REIMBURSEMENT, HIPAA, AND ASCA}

The original compliance date for the TCS rule for providers who conducted covered transactions electronically was October 16, 2002 (35). However, in December 2001 the Administrative Simplification Compliance Act (ASCA) was enacted to allow any physician who filed a compliance plan with HHS before October 16, 2002 an additional year to come into compliance with the TCS rule (36). The February 20, 2003 modification to the TCS rule addressed the issue of compliance with the TCS rule between October 16, 2002 and October 16, 2003 for entities that did not file a compliance plan, but the complex enforcement rules that apply to those entities are beyond the scope of this article.

ASCA also required all Medicare claims under Parts A and B to be filed electronically by October 16, 2003, unless a physician practice had less than 10 full-time equivalent employees (FTEs) or some other very limited exceptions applied (37). This has led many physician practices to the mistaken belief that if they have less than 10 FTEs, HIPAA does not apply to them. This is not true. The TCS rule does not compel you to conduct any of the covered transactions electronically, but if you conduct even one electronically, you are subject to all of the HIPAA rules, including the TCS rule, the privacy rule, and the security rule. ASCA simply states that if a physician practice has less than 10 FTEs, it can choose to file Medicare claims on paper. ASCA has nothing to do with whether a provider is subject to HIPAA.

One potential trap that physician practices should be aware of is that, if the practice has to conduct transactions electronically with Medicare because it does not meet the fewer than 10 FTE exception and has not conducted them before, the day that the practice conducts its first electronic transaction with Medicare or any other health plan or clearinghouse, it becomes automatically subject to the HIPAA privacy rule and must be in immediate compliance with it. There is no grace period.

\section{How to Get Reimbursed for Health} Care After October 16, 2003

Physicians have several options for conducting covered transactions, including filing claims, after October 16, 2003 (38).

- Continue submitting transactions, including claims, on paper. If health plans will accept them, you can continue to submit covered transactions on paper. Read your contract with your health plan carefully to determine if you can still submit paper claims. Someone from your office or your information technology (IT) vendor should have already reviewed your payers' websites and talked with them about their requirements (39).

- Paper or non-standard electronic transactions sent to a clearinghouse. A clearinghouse can take a paper or a non-standard electronic claim, convert it into the HIPAA required format, and submit it to payers. However, physician practices should assure themselves that their office is capturing all the necessary data for the clearinghouse to send a HIPAAcompliant claim to the payers (40).

Electronic transactions with standard content sent to a clearinghouse. Here, the physician works with its practice management or billing system vendor to make sure all HIPAA-required content is captured. The clearing- house then translates the claim or other transaction into the HIPAArequired format (41).

Direct data entry. A physician may use a "direct data entry" process, where data are directly keyed into a health plan's computer using dumb terminals or computer browser screens, if the payer offers this service. Direct data entry covered transactions must comply with the data requirements of the applicable standard, but need not comply with the format portion of the standard (42).

Electronic covered transactions that comply with HIPAA data and content requirements may be sent directly to the payer by the physician practice. This will require a system that can convert data to the $\mathrm{X} 12 \mathrm{~N}$ format and connectivity to the health plan. Not all health plans have the capability to perform all of the covered transactions electronically right now. They may direct a physician practice to use a clearinghouse to receive, process, or transmit an electronic covered transaction. If they do, they cannot charge fees or costs in excess of the fees or costs for normal telecommunications that a physician practice incurs when it directly transmits or receives a covered transaction electronically to or from a health plan (43).

At a minimum, physician practices must have the ability to capture the data required by the TCS rule for covered transactions conducted electronically, and either use a clearinghouse to translate the data to X12N format or obtain a translator and electronic connectivity to ensure that the practice can send electronically compliant claims by October 16, 2003 (44).

The TCS rule does not require physicians to submit claims transactions or any other transactions electronically, but all transactions submitted electronically must comply with the standards. For example, a physician could send an electronic health care claim standard transaction for Patient A to health plan Z, and could also send a paper claim for patient B to health plan Z, provided health plan $\mathrm{Z}$ still accepts paper claims. The same physician could send an electronic health care claim standard transaction to health plan $\mathrm{S}$ and send paper claims to health plan $\mathrm{T}$, 
provided health plan $\mathrm{T}$ still accepts paper claims. However, if your practice simply uses paper, telephones, faxes sent by a dedicated fax machine and not sent by a computer, then you are not subject to HIPAA or the TCS rule. As a practical matter, however, most health plans will probably begin to require that claims be filed electronically or assess an additional fee for processing paper claims and other covered transactions not submitted electronically (45).

Under HIPAA, health plans must accept the standard claim submitted electronically. They cannot:

- require physicians to make changes or additions to the standard claim;

- delay or reject a transaction, or attempt to adversely affect a physician practice or the transaction, because the transaction is a standard one;

- reject a standard transaction on the basis that it contains data elements not needed or used by the health plan; or

- offer incentives for physicians to conduct a transaction covered by the TCS rule as a direct data entry (46).

Until a standard is adopted for electronic health claims attachments and compliance is required with that standard, health plans can continue to require health claim attachments to be submitted on paper (47).

\section{Trading Partner Agreements and Business Associate Agreements}

Trading partner agreements are agreements relating to the exchange of information in electronic transactions. They may specify the duties and responsibilities of each party to the agreement in conducting a covered transaction electronically, but they are not required under HIPAA (48). They might be particularly helpful in specifying electronic security and connectivity requirements and indemnification duties of the parties, e.g., which party will ultimately pay for costs incurred by security breaches (49). The TCS rule, however, does specify that physician practices cannot enter into a trading partner agreement that would do any of the following:

- change the definition, data condition, or use of a data element or segment in a standard;
- add any data elements or segments not in the maximum defined data set in the applicable implementation guide;

- use any code or data elements that are either marked "not used" in the implementation specifications or are not in the standard's implementation specifications; or

- change the meaning or intent of a standard's implementation specifications (50).

Similarly, provider contracts with health plans and health plan administrative manuals cannot provide for any of the above. This means that physicians choosing to engage in electronic transactions covered by the TCS rule must review their provider contracts with health plans and revise them so that renewals of the contracts occurring on and after October 16, 2003 state that electronic standard transactions must comply with the regulation (51).

Physicians may choose to use a business associate (a person who performs an activity falling under the TCS rule on behalf of the physician), including a health care clearinghouse, to conduct electronic covered transactions for them. However, the physician must contractually require the business associate (1) to comply with all applicable requirements of the TCS rule and (2) to insist via written contract that the business associate's agents and subcontractors comply with the TCS rule (52). Such business associate agreements must also meet the requirements of the HIPAA privacy rule and, by April 20,2005 , the requirements of the security rule (53).

\section{ENFORCEMENT AND IMPLEMENTATION}

HIPAA gives the Secretary of HHS the authority to impose monetary penalties for failure to comply with a standard. The Secretary is required by statute to impose penalties of not more than $\$ 100$ per violation on any person or entity who fails to comply with a standard. However, the total amount imposed on any one person in each calendar year cannot exceed $\$ 25,000$ for violations of one requirement (54).

CMS, a department of HHS, recently issued guidance on its enforcement of the TCS rule after the October 16, 2003 deadline. It will focus on obtaining voluntary compliance and will use a complaint-driv- en approach. When CMS receives a complaint about a physician practice, it will notify the practice in writing that a complaint has been filed. The practice will then have the opportunity to:

- demonstrate that it has complied with the TCS rule;

- submit a corrective action plan; and/or

- document its good faith efforts to comply with the TCS rule. If the failure to comply is based on reasonable cause and is not due to willful neglect, and the failure to comply is cured within 30 days of notice from HHS, then HHS cannot impose a civil penalty. HHS has the authority to extend the period within which the practice may cure the noncompliance.

Significantly, CMS will not impose penalties on health plans that continue to pay non-compliant electronic covered transactions if the health plan can demonstrate active outreach/testing efforts with its providers. The bottom line is simple: to avoid fines, a practice must be able to document that it took action prior to October 16, 2003 to become compliant and that it is continuing efforts to correct any deficiencies in its electronic covered transactions (55).

\section{Practices That Have not Begun or Steps Towards ComplaAnce}

A practice that conducts covered transactions electronically should have filed its compliance plan with HHS before October 16, 2002, should have started testing with its clearinghouses and payers by April 16, 2003, and should be ready for compliance by October 16, 2003. If a practice has not completed all those steps, it should immediately appoint a person to be in charge of implementation and should immediately begin investigating resources available on the internet. Besides the CMS website (http: //cms.hhs.gov/hipaa/hipaa2/default.asp), which contains training tools and short, practical advice sheets, one of the most useful tools available is the HIPAA Transactions and Code Sets Toolkit, available at http://onlinepressroom.net/bcbsa/ (click on 6/12/2003 Release regarding the toolkit, then click on the link to the toolkit in the article). 


\section{Author Affiliation:}

Erin Brisbay McMahon, JD

Wyatt, Tarrant \& Combs

250 W. Main St., Suite 1600

Lexington, KY 40507

E-mail: emcmahon@wyattfirm.com

\section{REFERENCES}

1. 65 Fed. Reg. 50,312.

2. 42 U.S.C. § 1320d-2.

3. CMS, Implementation of Administrative Simplification Requirements by HHS (available on the web at http:// cms.hhs.gov/hipaa/hipaa2/general/ background/kkimpl.asp).

4. 65 Fed. Reg. 70,507.

5. 68 Fed. Reg. 8,381.

6. 45 C.F.R. $160.102,162.100$

7. 45 C.F.R. 160.103.

8. 45 C.F.R. 160.103.

9. CMS, Frequently Asked Questions, Answer ID 1572 (available on the web at http://questions.cms.hhs.gov/cgi-bin/ cmshhs.cfg/php/enduser/std_alp.php).

10. 45 C.F.R. 162.1101.

11. 45 C.F.R. 162.1501.

12. 45 C.F.R. 162.1201.

13. 45 C.F.R. 162.1601.

14. 45 C.F.R. 162.1701.

15. 45 C.F.R. 162.1401.

16. 45 C.F.R. 162.1301.

17. 45 C.F.R. 162.1801.
18. 42 U.S.C. $\S 1320 d-2(a)(2)$.

19. 45 C.F.R. 162.940.

20. 42 U.S.C. § 1320d(8); 42 U.S.C. § 1320d$1(c)$.

21. See Margret Amatayakul, HIPAA Transactions and Code Sets Toolkit at 11, http:// onlinepressroom.net/bcbsa/ (click on 6/ $12 / 2003$ Release regarding the toolkit, then click on the link to the toolkit in the article).

22. 45 C.F.R. 162.1102; Amatayakul, supra note 21 , at 11 .

23. 45 C.F.R. 162.1502; Amatayakul, supra note 21 , at 11 .

24. 45 C.F.R. 162.1202; Amatayakul, supra note 21 , at 11.

25. 45 C.F.R. 162.1602; Amatayakul, supra note 21 , at 11 .

26. 45 C.F.R. 162.1702; Amatayakul, supra note 21 , at 11 .

27. 45 C.F.R. 162.1402; Amatayakul, supra note 21 , at 11 .

28. 45 C.F.R. 162.1302; Amatayakul, supra note 21 , at 11 .

29. 45 C.F.R. 162.1002.

30. 45 C.F.R. 162.1002.

31. 45 C.F.R. 162.1002

32. 45 C.F.R. 162.1002.

33. 45 C.F.R. 162.1002

34. 45 C.F.R. Part 162.

35. 65 Fed. Reg. 50,368.

36. Pub. Law 107-105 (Dec. 27, 2001).

37. Pub. Law 107-105 (Dec. 27, 2001).

38. Amatayakul, supra note 21 , at 9.
39. Amatayakul, supra note 21, at 9.

40. Amatayakul, supra note 21, at 9.

41. Amatayakul, supra note 21 , at 9.

42. 45 C.F.R. 162.923(b); Amatayakul, supra note 21 , at 9 .

43. 45 C.F.R. 162.925(a)(5); Amatayakul, supra note 21, at 9.

44. Amatayakul, supra note 21 , at 15 .

45. CMS, Frequently Asked Questions, Answer ID 1572 (available on the web at http://questions.cms.hhs.gov/cgi-bin/ cmshhs.cfg/php/enduser/std_alp.php).

46. 45 C.F.R. 162.925 (a).

47. CMS, Frequently Asked Questions, Answer ID 1469 (available on the web at http://questions.cms.hhs.gov/cgi-bin/ cmshhs.cfg/php/enduser/std_alp.php).

48. Richard D. Marks, "Surviving Standard Transactions: A HIPAA Roadmap," 12 Health Law Reporter 901, 909-10 (Jun 5, 2003).

49. Richard D. Marks, "Surviving Standard Transactions: A HIPAA Roadmap," 12 Health Law Reporter 901, 909-10 (Jun 5, 2003).

50. 45 C.F.R. 162.915.

51. See 45 C.F.R. 162.915.

52. 45 C.F.R. $162.923(\mathrm{c})$.

53. 45 C.F.R. $164.504($ e); 45 C.F.R. $164.314(a)$.

54. 42 U.S.C. § 1320d-5.

55. CMS, "Guidance on Compliance with HIPAA Transactions and Code Sets after the October 16, 2003, Implementation Deadline (available on the web at http: //cms.hhs.gov/hipaa/hipaaz/guidancefinal.pdf).

\section{Important Addendum}

As we went to press, CMS announced that it would accept noncompliant electronic transactions after the October 16, 2003 compliance deadline. CMS will process HIPAA-compliant electronic transactions and covered transactions in the electronic formats now in use. CMS has not indicated how long it will maintain what amounts to two electronic payment systems. This contingency plan does not allow providers with 10 or more FTEs to file paper claims. Also keep in mind that practices that send noncompliant electronic transactions to CMS are asking for an investigation as to why they were not ready to submit compliant transactions by the deadline. For more information, visit http://www.cms.gov/media/press/release.asp?Counter $=870$ 
